\title{
DOS PROYECTOS DE URBANIZACIÓN EN SANTIAGO
}

\author{
( TWO URBANIZATION PROJECTS IN SANTIAGO )
}

José Luis Pérez Franco, Arquitecto

Fecha de recepción: 30-VI-95

ESPAÑA

\author{
RESUMEN \\ En el presente articulo se describen dos actuaciones de \\ mejora de la urbanización en la ciudad de Santiago. Se trata \\ de la recuperación de las riberas del rio Sarela en el barrio \\ del Carmen deAbaixo y el acondicionamiento del Conjunto \\ del Parque de la Alameda y Paseo de la Herradura en el Coto \\ de Santa Susana. \\ Ambas actuaciones se producen en el ámbito de la ciudad \\ histórica $y$, si bien abordan problemas formales y funcionales \\ diferentes, coinciden en el empleo de los materiales \\ tradicionales sin por ello renunciar a la posibilidad de \\ proyectar y construir desde una posición contemporánea.
}

\section{SUMMARY}

This article describes two actions of urbanization improvement in the city of Santiago. They are the reclamation of the shores of the Sarela river in the Carmen deAbaixo quarter and the arrangement of the Parque de la Alameda and Paseo de la Herradura Complex in the Santa Susana Reserve.

Both actions are produced within the historical part of the city and although they deal with different formal and functional problems, they coincide in the use of traditional materials without the need to give up the possibility to undertake design and construction from a contemporary standpoint.

\section{Acondicionamiento de la ribera del Sarela en el Carmen de Abaixo}

El barrio del Carmen de Abaixo es un antiguo rueiro situado en el Noroeste de la ciudad de Santiago. Se accede al mismo por la calle Cruceiro de Gaio a través de la calzada do Carmen de Abaixo que desciende con fuerte pendiente hacia el río.

En el entorno del viejo puente de piedra sobre el Sarela se encuentran los espacios públicos más característicos del barrio. La pequeñaiglesia del Carmen con su atrio, un viejo molino, la fuente situada en el arranque del puente y una amplia zona libre generada por sucesivos rellenos, sugerían la posibilidad de una actuación reurbanizadora de estos espacios, consolidando el itinerario peatonal que une el fin de la calle Entre Galeras con el rueiro de Figueiriñas. El río actuará como soporte paisajístico y límite de esta actuación.

Asimismo, laconstrucción del Colegio deEGB (proyectado por G. Grassi), la rehabilitación y cambio de uso de las antiguas curtidurías del rueiro de Figueiriñas y, en general, 

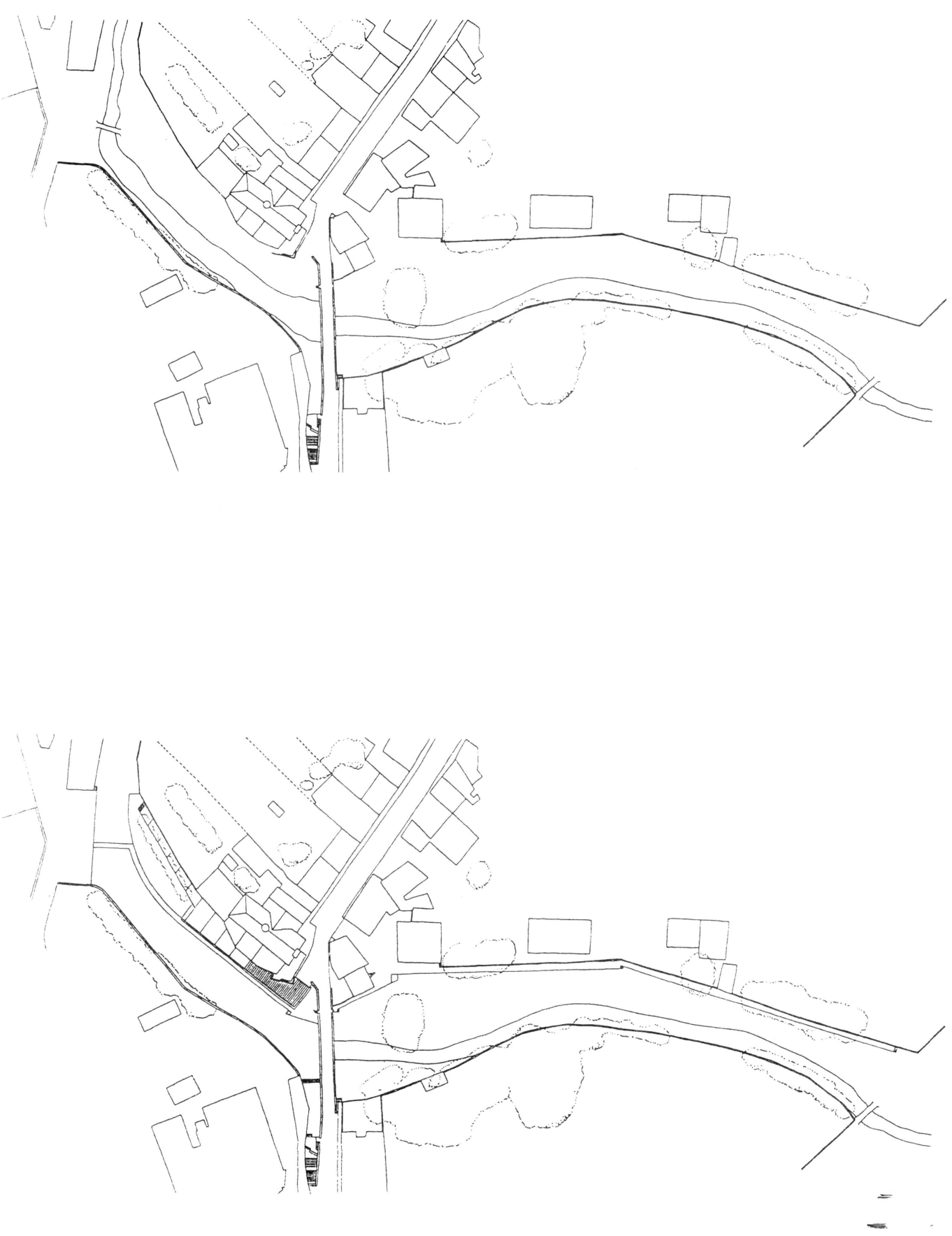

Fig. 1.- Carmen de Abaixo. Estado inicial y Proyecto. 


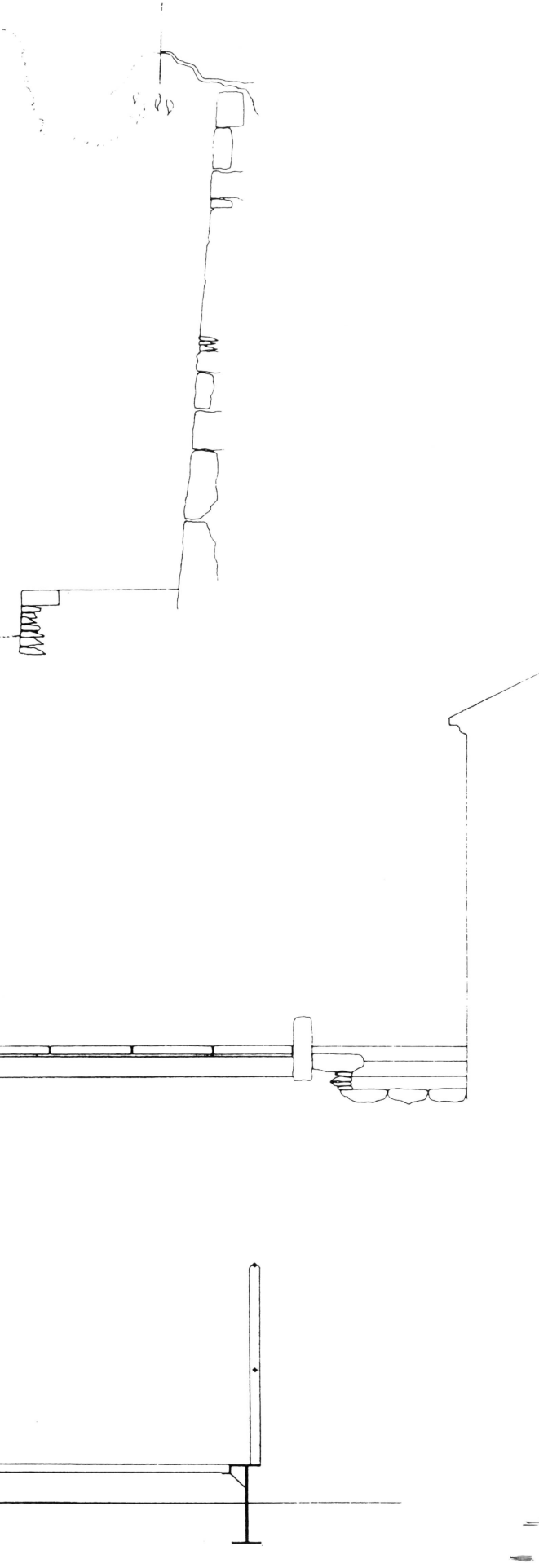

Secciones constructivas.

(c) Consejo Superior de Investigaciones Científicas 


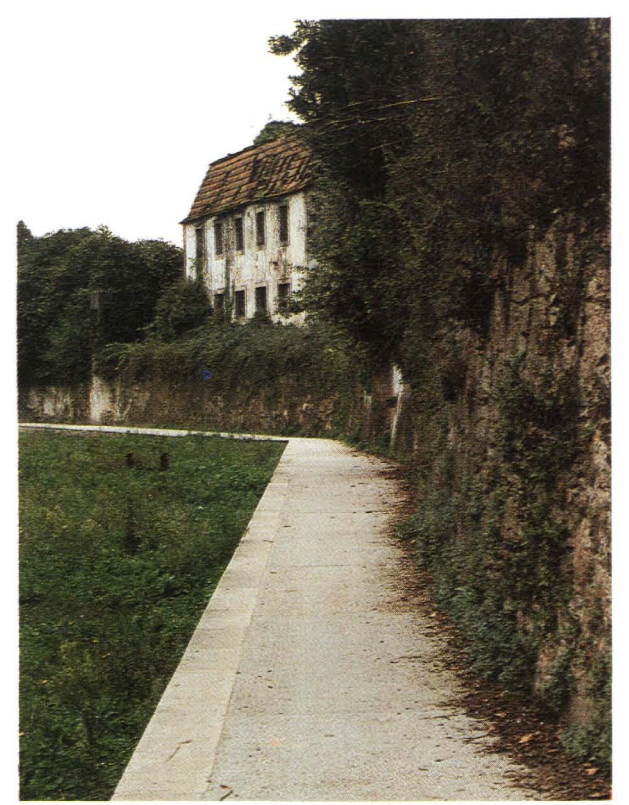

Fig. 2.- Camino peatonal entre las rúas Entre Galeras y Carmen de Abaixo. los usos establecidos en el Plan Especial para las grandes fincas que se encuentran en la zona, justifican la oportunidad de esta intervención (Fig. 1).

Por otra parte, lo proyectado debería ayudar a resolver el problema de las inundaciones que se producen en este tramo del Sarela. Las crecidas naturales del río se agravan por el incremento de caudal producido por los vertidos de la red de saneamiento de esa zona. Además, al haberse rellenado el canal de abastecimiento al molino cegando uno de los vanos del puente, se ha producido una reducción significativa del cauce natural.

Aguas arriba del puente, el proyecto define un itinerario peatonal que comienza en el final de la rua Entre Galeras, discurre adosado al muro de cierre de la finca de la "vaquería de Daporta" y desemboca en una pequeña plaza irregular desde la que se accede a la calle del Carmen de Abaixo. Este tramo del paseo se configura comoun estrecho andén elevado $50 \mathrm{~cm}$ sobre la rasante natural de forma que los desbordamientos del Sarela no impiden su uso.

El trazado rectilíneo y su dimensión doméstica valoran, por contraste, el carácter orgánico y monumental del muro de piedra existente. La ubicación de este paseo recuerda el trazado del antiguo canal de abastecimiento al molino, a la vez que busca liberar el máximo de terreno de la ribera para no interferir en la futura configuración de esa zona verde. Los encuentros entre los tramos rectos del trazado se aprovechan para generar pequeñas escaleras y rampas de acceso a la ribera (Fig. 2)
En el entorno de la iglesia, se proyecta un nuevo atrio pavimentado en piedra y rematado por un muro de cantería que sirve de banco. Adosado al mismo y elevado sobre la rasante, se construye un muelle que permite el recorrido peatonal hasta el nuevo puente metálico de acceso al rueiro de Figueiriñas. Este muelle define en su tramo curvo un espacio libre pavimentado en tierra en el que se construirá un parque infantil, aprovechando su óptimo soleamiento y su proximidad a las viviendas proyectadas en la rehabilitación de las antiguas edificaciones de la curtiduría (Figs. 3 y 4 ).

El trazado del nuevo atrio es paralelo a las alineaciones definidas por la iglesia del Carmen, reconociendo así el papel ordenador de los monumentos en relación al espacio público. El banco de sillería refuerza la presencia del pre-

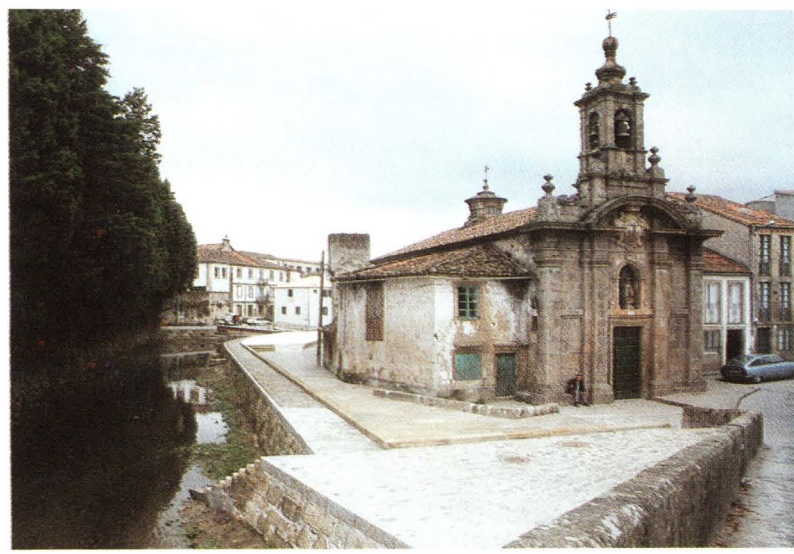

Fig. 3.- Aspecto general del muelle y el nuevo atrio.

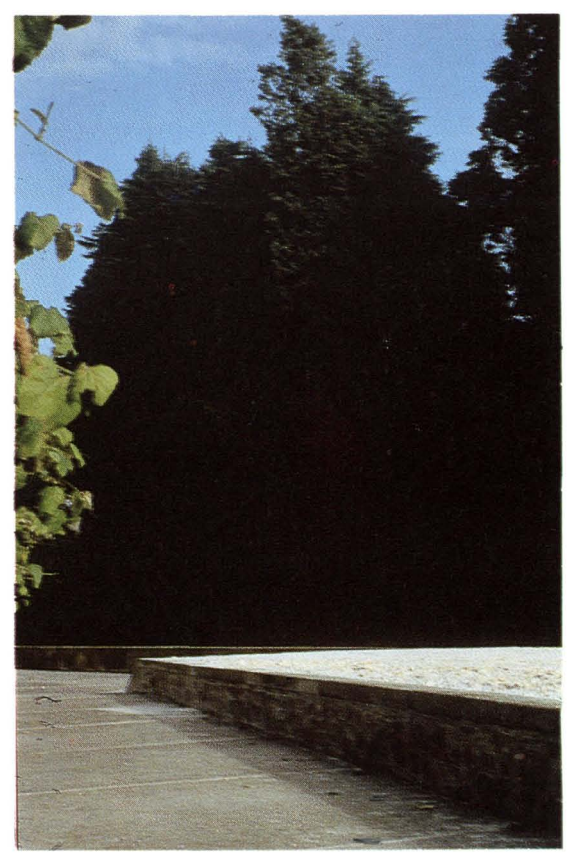

Fig. 4.- Zona de juegos infantiles. 


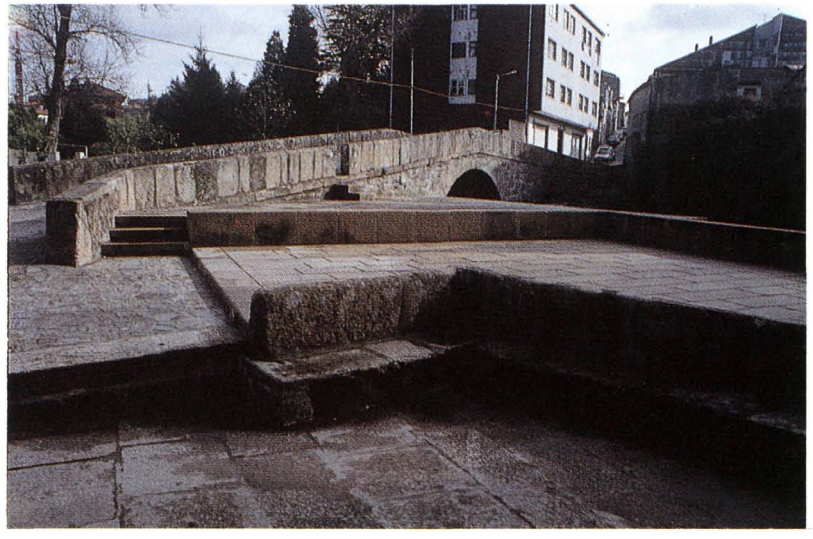

Fig. 5.- Antiguo y nuevo atrio de la iglesia del Carmen.

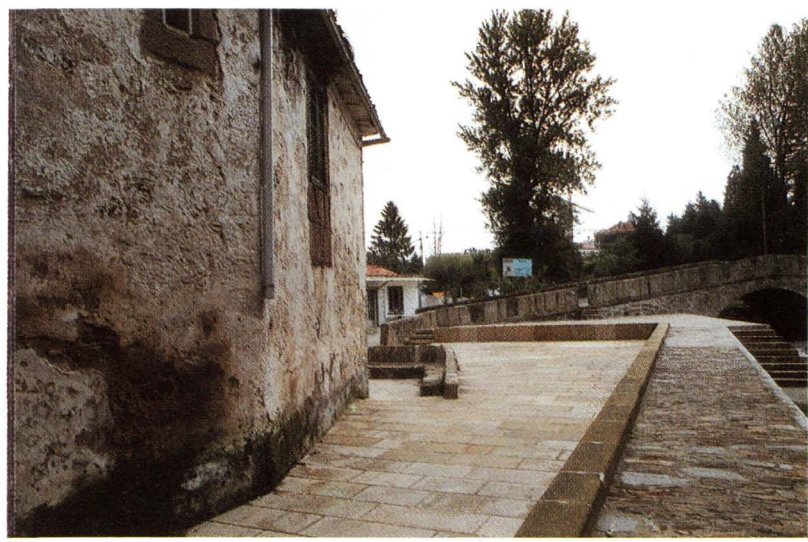

Fig. 6.- Muelle peatonal.

til de puente y repite, como un eco, la imagen del antiguo atrio definido por el banco de piedra preexistente (Fig.5).

Los materiales empleados ayudan a jerarquizar los espacios definidos en este área. El atrio se pavimenta con losas rectangulares de granito silvestre de $15 \mathrm{~cm}$ de espesor, subrayando la importancia de este espacio previa a la iglesia (Fig. 6). El muelle se ejecuta en mampostería de granito gris y se pavimenta con losas irregulares de pizarra (chapacuña) colocadas sobre cama de arena según la técnica tradicional. Al otro lado del río se procedió a la recuperación y puesta en uso de una antigua fuente a la que se accede por escaleras desde la base del puente.

\section{Acondicionamiento del conjunto del Parque de la Alameda y Herradura en el Coto de Santa Susana}

El coto de Santa Susana es, sin duda, el espacio verde más emblemático de la ciudad de Santiago. Se trata de un conjunto de jardines y paseos dispuestos alrededor del monte de Santa Susana. Sus espacios más diferenciados son los jardines situados frente al colegio San Clemente, el parque de la Alameda y el llamado paseo de la Herradura que rodea a la carballeira de Santa Susana (Fig. 7).

El proceso de remodelación del conjunto se inició en el año 1990 , redactándose un proyecto para acondicionar los jardines que comunicaban porta Faxeira (antigua salida natural extramuros) con el coto de Santa Susana. Estos jardines estaban pavimentados en tierra y soportaban un uso muy intenso por ser la comunicación peatonal más importante entre el casco antiguo, el ensanche y el conjunto del parque.

La actuación en esta zona consistió en el trazado de dos plazas regulares dispuestas reforzando el eje Norte-Sur definido por el claustro del antiguo colegio San Clemente (Fig. 9), la pavimentación con enlosado de granito silvestre de todo el conjunto, así como la reposición de los servicios de alcantarillado, alumbrado, riego y diversas mejoras en la jardinería (Figs. 10, 11 y 12).

\subsection{Acondicionamiento de la Alameda}

El trazado decimonónico de la Alameda se asienta en los terrenos del llamado "Campo daEstrela"- Este lugar ya era utilizado como espacio libre para ferias, mercados y actos públicos desde que en 1546 sus propietarios, los condes de Altamira, lo cediesen a la municipalidad (Fig. 8).

Su actual configuración se inicia en el período 1835-1850 y su trazado está inspirado en las promenades francesas y más directamente en su versión española de "salón urbano".

Inicialmente se construyeron dos grandes paseos denominados de Madrid y de París; estos paseos sufren sucesivas reformas en el período 1870-1900 hasta llegar a su configuración actual.

El paseo que está situado al Sur es tangente a la avda. Juan Carlos I y su rasante se sitúa dos metros por encima de ésta por medio de un muro de cantería que continúa la alineacióndefinida por la Iglesia del Pilar. La superficie de este salón está ocupada en su mayor parte por un conjunto de tres estanques unidos entre sí, rodeados de césped, y que se recorren lateralmente por dos paseos que desembocan en un espacio previo a la iglesia.

Los salones restantes están dispuestos jerarquizando el paseo central que define y organiza todo el conjunto. A ambos lados del mismo se encuentran dos paseos de menor ancho que rematan en la escalera de piedra de acceso a la Herradura.

La separación entre estos paseos se produce por hileras de árboles plantados en alcorques rectangulares y bancos de piedra y fundición producidos en las Reales Fábricas de Sargadelos (Fig. 11). 


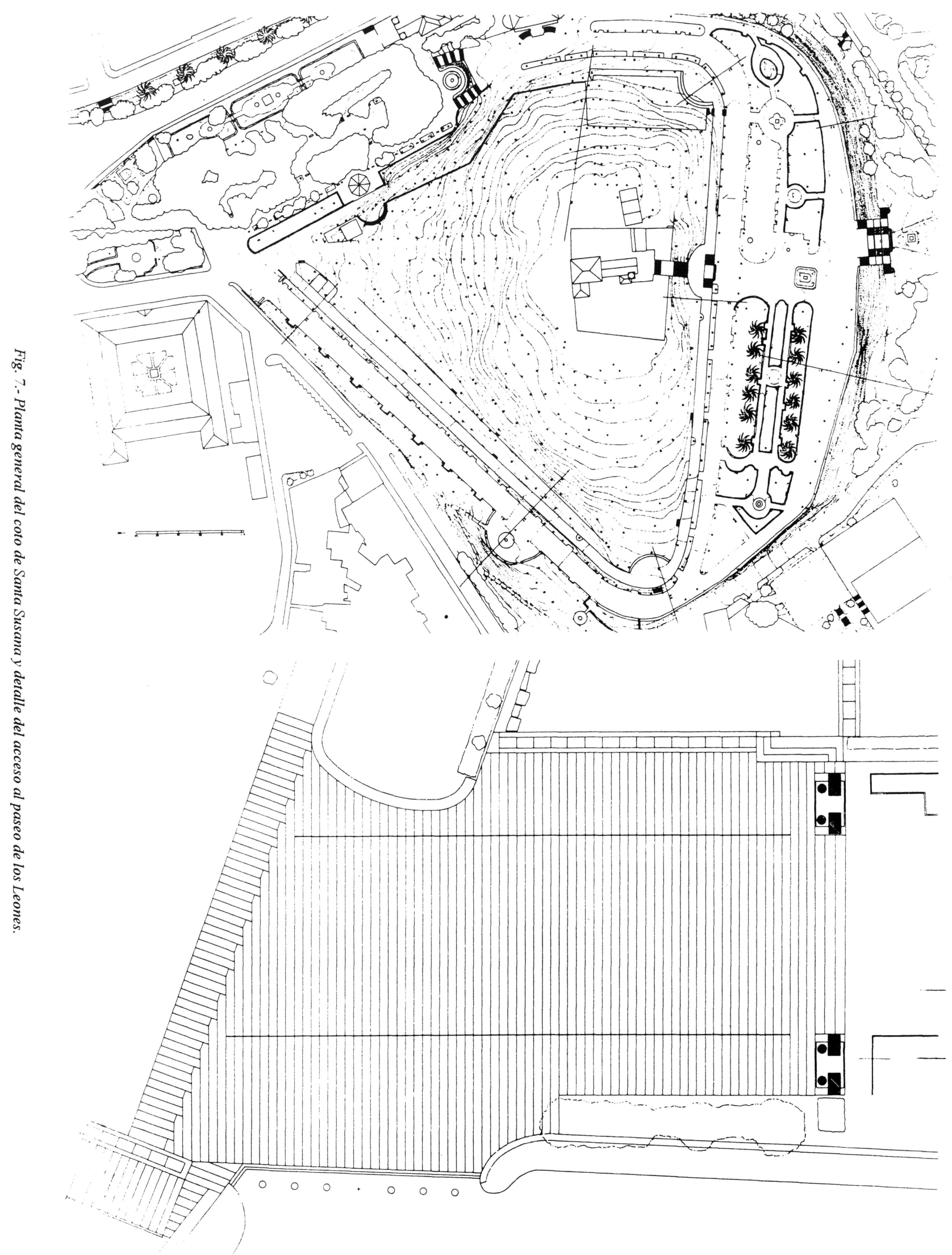




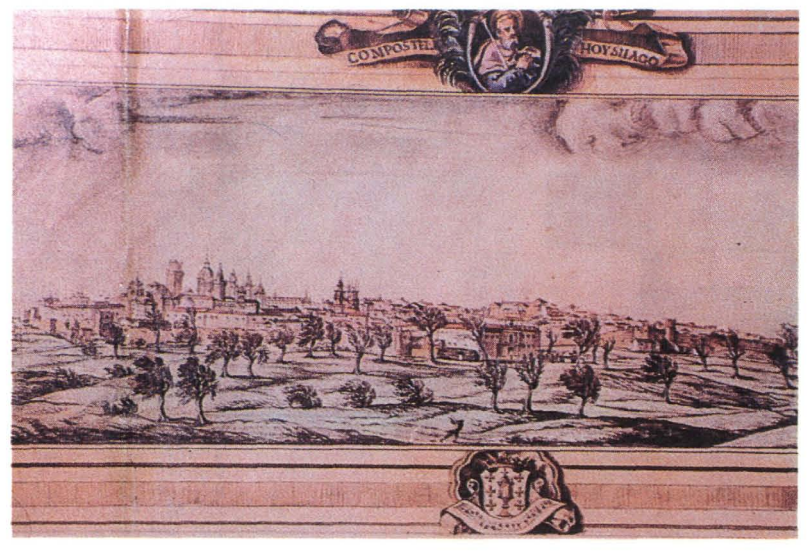

Fig. 8. - La ciudad de Santiago desde el "Campo daEstrela". Hustr. de Pier $M^{\mathrm{a}}$ Baldi (h. 1668).

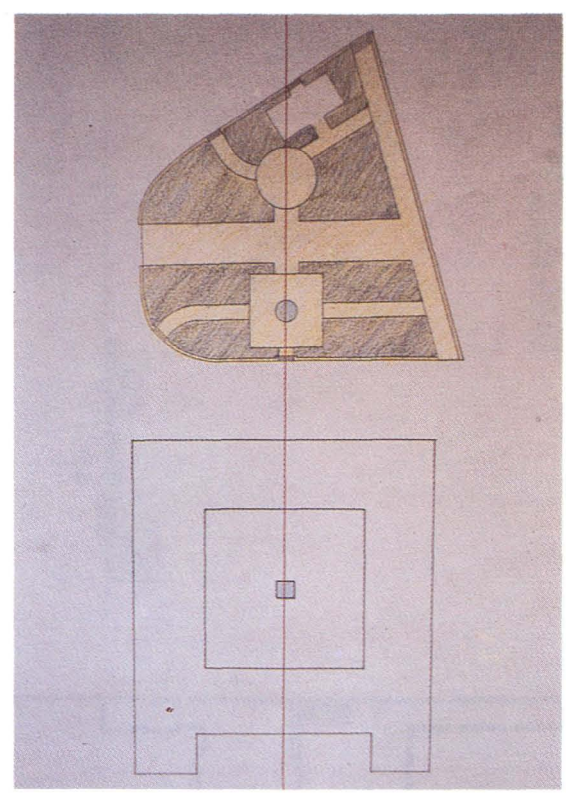

Fig. 9.- Planta de remodelación de los jardines de la Alameda.

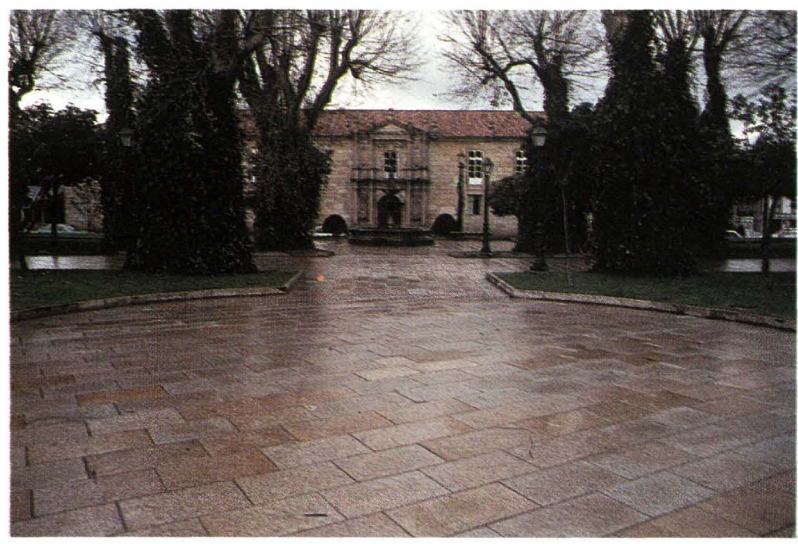

Fig. 10.- Jardines de acceso a la Alameda. Aspecto general desde el eje de las plazas.

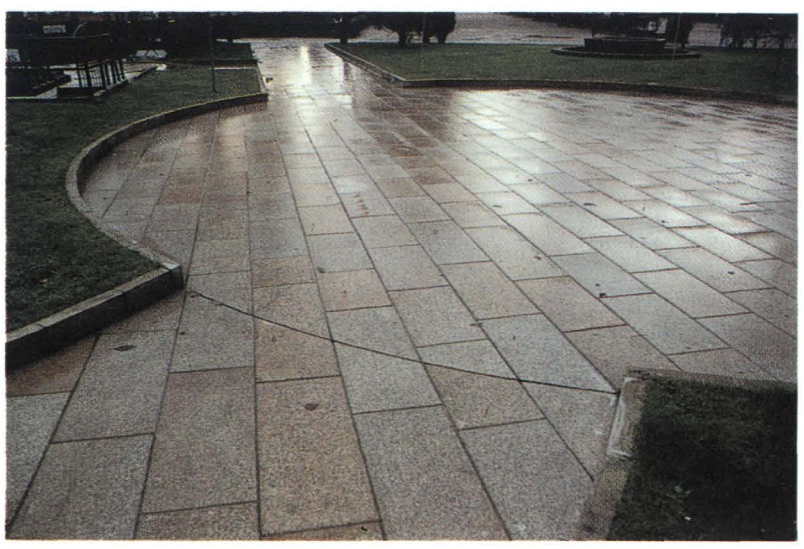

Fig. 11.- Jardines de acceso a la Alameda. Plaza circular.

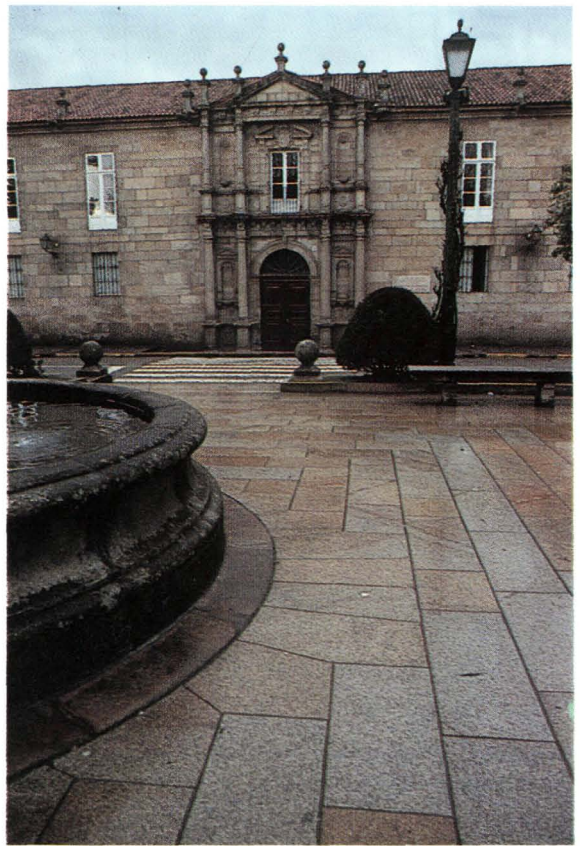

Fig. 12.- Jardines de acceso a la Alameda. Plaza cuadrada.

La pavimentación de todo el conjunto era de jabre compactado que periódicamente había que reponer debido a que en algunas zonas las pendientes eran excesivas, por loque se producía el arrastre del pavimento hacia cotas más bajas. El sistema de recogida de aguas consistía en atarjeas de hormigón, muy deterioradas, siendo necesaria su sustitución.

En laintervención sobre la Alameda se habuscado respetar al máximo las características ambientales y de trazado sin renunciar a la necesaria restauración de las infraestructuras y del amueblamiento (Fig. 13).

En el ámbito del paseo central era necesaria la sustitución de los alcorques actuales, muy deteriorados, y la restauración y rasanteo de los bancos de piedra situados entre los 

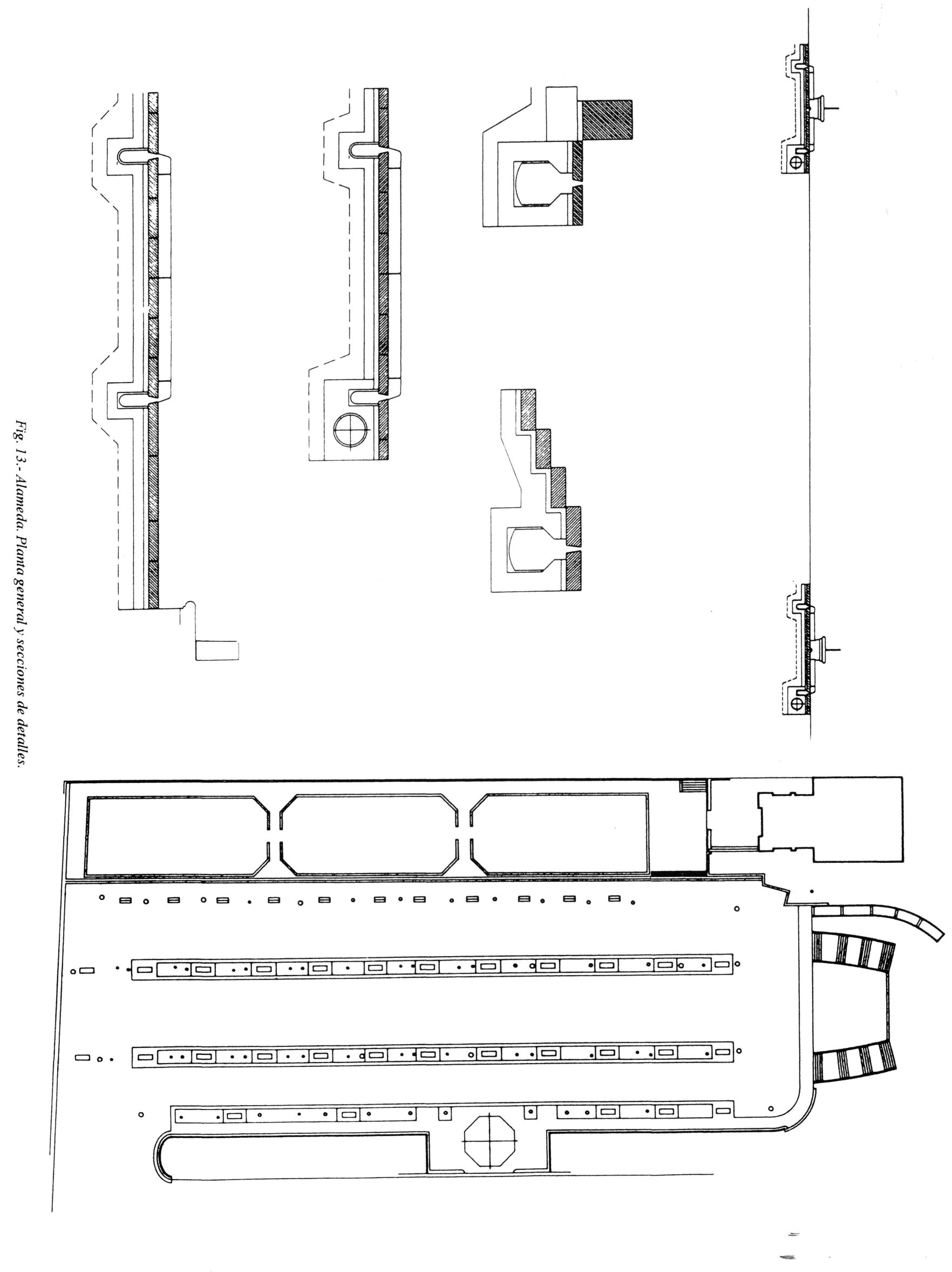


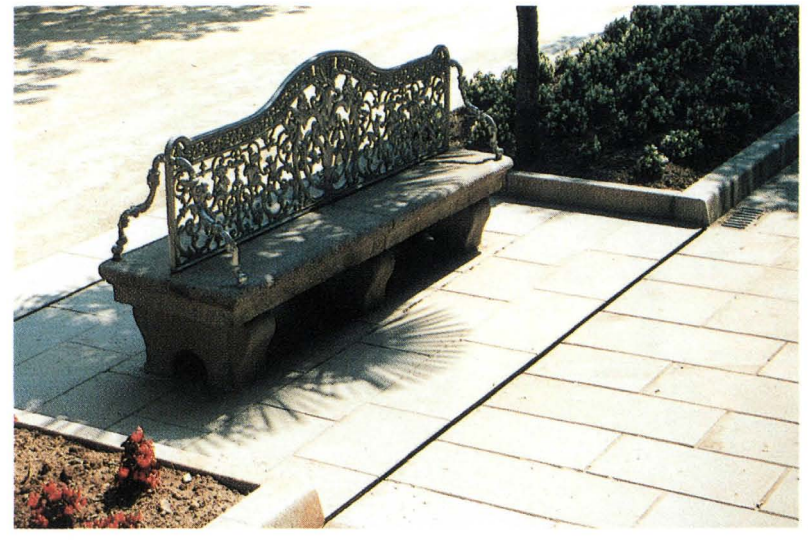

Fig. 14.- Bancos de piedra y fundición de los talleres de Sargadelos.

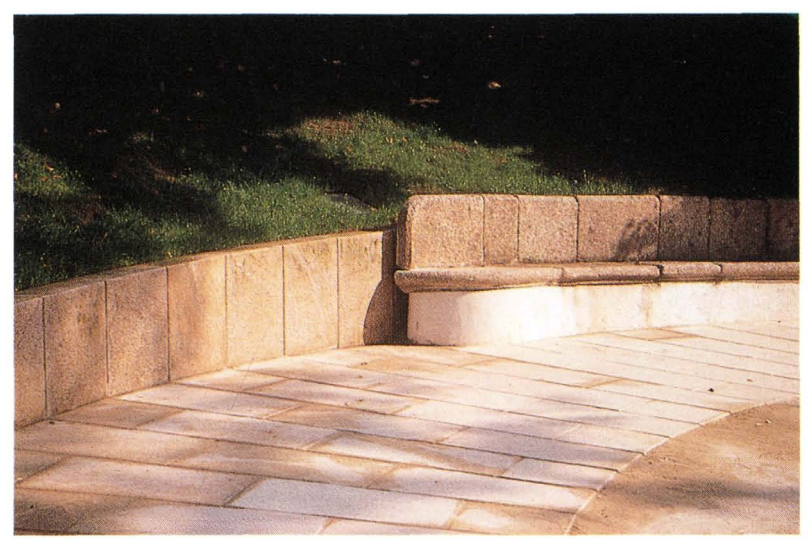

Fig. 15.- Remate del banco de piedra de Prado y Ballo (h. 1860).

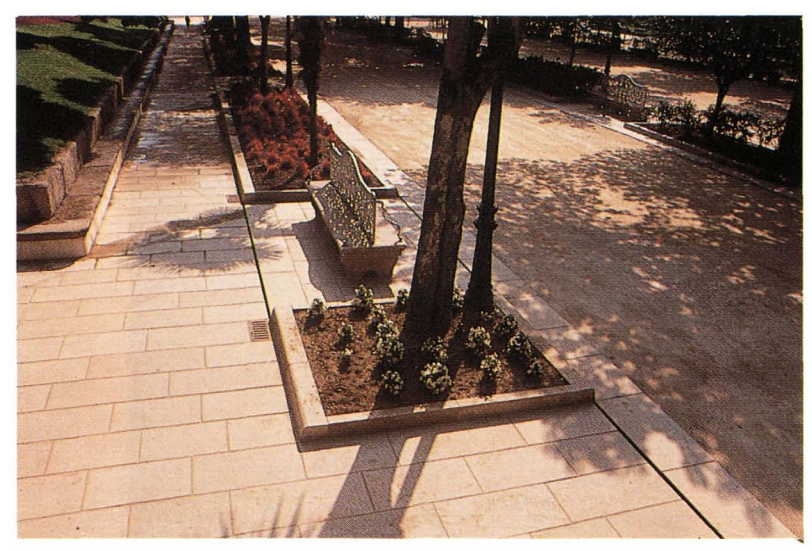

Fig. 16.- Paseo del palco de música.

alcorques. Aparecía así la oportunidad de construir una superficie más duradera sobre la que reubicar dichos bancos. Todo ello debería compatibilizarse con el trazado y construcción de un nuevo sistema de recogida de aguas.
La necesidad de resolver estas tres funciones en un espacio muy estrecho, sugirió la posibilidad de dibujar un único elemento que, a modo de gran mueble urbano, cumpliese dichas funciones garantizando la unidad formal del conjunto. Así, se proyectaron dos plataformas pétreas de 3,7 $\mathrm{m}$ de ancho por $107 \mathrm{~m}$ de largo enrasadas con el pavimento de tierra. Sobre esta superficie se dibujan con claridad los espacios destinados a alcorques y bancos.

El diseño de los elementos que materializan la plataforma, procura reforzar la linealidad y unidad de esta superficie. Al diferenciar la sección de los bordillos transversales y longitudinales del alcorque y unir visualmente estos últimos por medio de una junta de $3,5 \mathrm{~cm}$ que funciona comio sumidero, se sugiere la idea de un único alcorque de $107 \mathrm{~m}$ de largo, interrumpido regularmente para ubicar los ban$\cos$ (Fig. 14).

En el paseo situado al Norte, en el límite de la Carballeira de Santa Susana, se propone la pavimentación en piedra de un pequeño andén de dos metros de ancho que sirva de base del banco corrido de piedra (diseñado por Prado y Ballo hacia 1860) y el palco de la música, recientemente restaurado (Fig. 15).

Los alcorques existentes se mantienen en su posición, si bien se altera levemente su trazado con el objeto de regularizar su geometría. Del mismo modo, la pavimentación se extiende al espacio libre entre alcorques, siguiendo el criterio con el que se actúa en los bancos de piedra del paseo central.

La oportunidad de esta pavimentación aparece justificada por la presencia del palco de la música, cuya ubicación en posición centrada y retranqueando sobre la alineación definida por el banco de piedra, configura un espacio de remanso añadido al propio paseo. Desde este espacio se accede, a través de una escalera metálica, al camino que bordea la carballeira de Santa Susana en su lado Sur y que comunica con el Paseo de la Herradura.

La pavimentación en esa zona complementa la función formal de zócalo, desempeñada por el banco de piedra existente y cualifica el espacio definido por el palco de la música, sirviendo de transición entre el plano horizontal del conjunto de la Alameda y el monte de Santa Susana (Fig. 16).

En el paseo Sur, en la zona de la iglesia del Pilar, se modifican levemente las rasantes con el objeto de evitar la excesiva pendiente transversal que provocaba el arrastre del pavimento (Fig. 18).

Esta diferencia de rasante se soluciona con la construcción de una escalera que remata en un muro de $45 \times 45 \mathrm{~cm}$ de sección y que funciona como banco y muro de contención, análogo al que existe en la zona del palco de música, 
definiendo un nuevo atrio pavimentado en piedra (Figs. 19 y 20).

El resto de la intervención consiste en la sustitución de la atarjea de hormigón existente, por otra nueva de piedra que funciona como remate y contención del pavimento de tierra, cerrandoun anillo pavimentado que permite recorrer los bordes de la Alameda (Fig. 21).

\subsection{Acondicionamiento del Paseo de la Herradura}

Desde un lateral del rectángulo ocupado por la Alameda se inicia el paseo de la Herradura que recorre el perímetro del coto de Santa Susana, proporcionando las mejores vistas sobre el casco histórico de Santiago y las laderas del Monte Pedroso.

El mencionado paseo comenzaba en un espacio confuso en el que confluyen otros itinerarios, siendo el principal punto de acceso de peatones y vehículos al coto. La intervención consistió en formalizar una plaza pavimentada en piedra, cuyos límites se dibujan con claridad, continuando las alineaciones definidas por la calle Pombal, la Alameda y los antiguos pórticos de piedra previos al paseo de los Leones. Dos sumideros lineales, que prolongan la alineación del paseo hasta su contacto con la Alameda,ayudan a organizar este espacio (Figs. 17 y 22).

La actuación sobre el paseo consiste en la sustitución de los bordillos y la pavimentación en piedra de los espacios retranqueados en los que se ubican bancos de madera. El criterio es análogo al utilizado en la Alameda, pavimentándose únicamente los bordes laterales con una

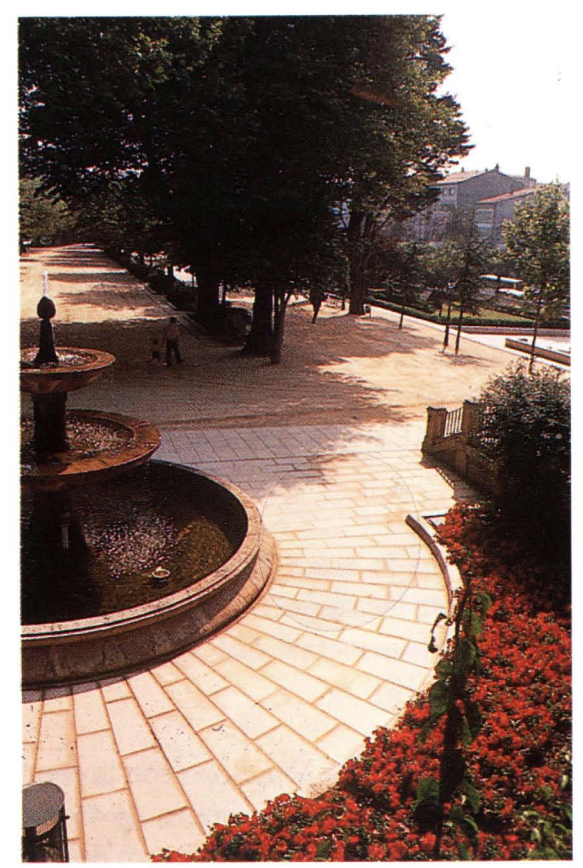

Fig. 17.- La Alameda desde el final de la Herradura

(c) Consejo Superior de Investigaciones Científicas Licencia Creative Commons 3.0 España (by-nc)

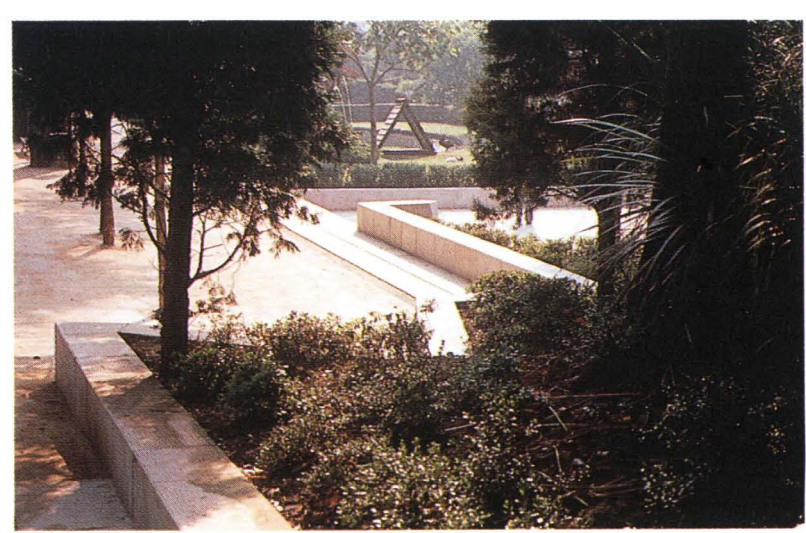

Fig. 18.- Muro quebrado de unión entre Alameda e iglesia del Pilar.

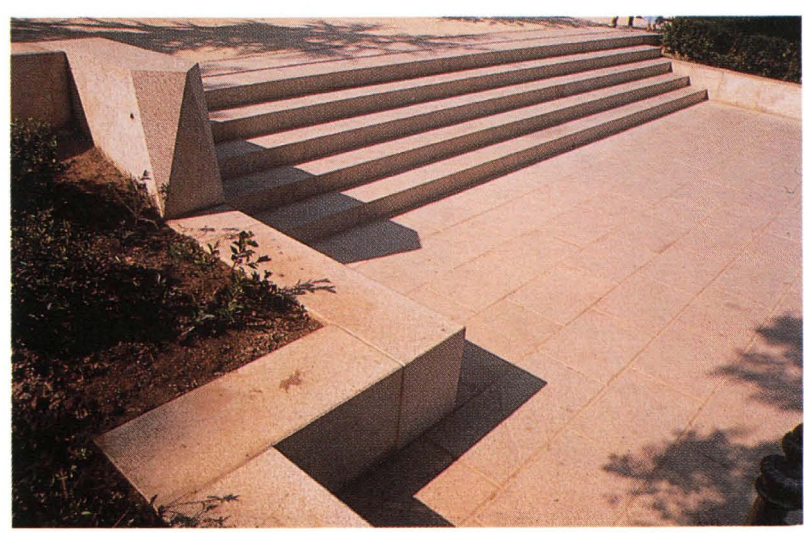

Fig. 19.- Nuevo atrio de la iglesia del Pilar.

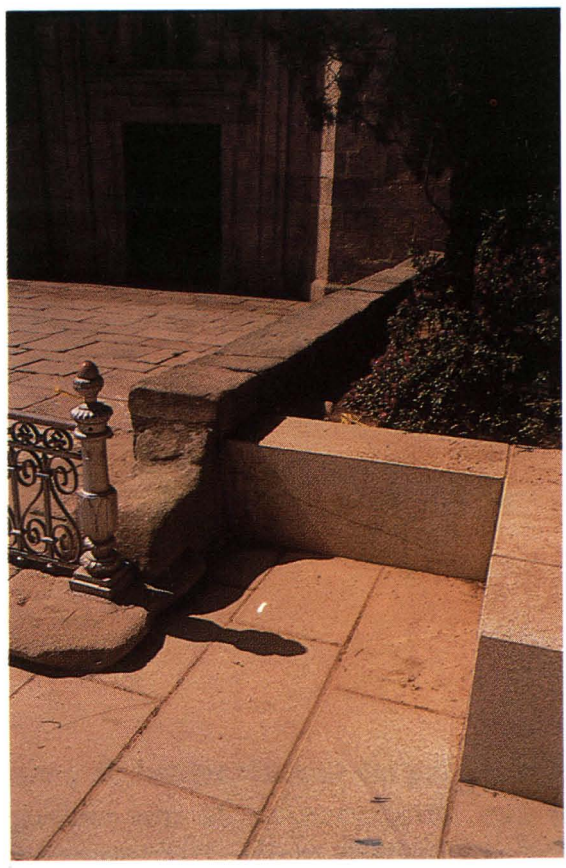

Fig. 20.- Nuevo y viejo atrio en la iglesia del Pilar. 
hilada de piedra de $50 \mathrm{~cm}$, enrasada con el pavimento de tierra, y bajo la que se alojan los servicios de pluviales y alumbrado (Figs. 23 y 24).

El paseo sobre los jardines del Campus se resuelve de forma similar para evitar el arrastre del firme de tierra hacia el talud existente (Figs. 25, 26 y 27).

El resto de la intervención sobre el coto consistió en la restauración de las pendientes naturales de la carballeira, la limpieza de las fuentes y monumentos, la ejecución de

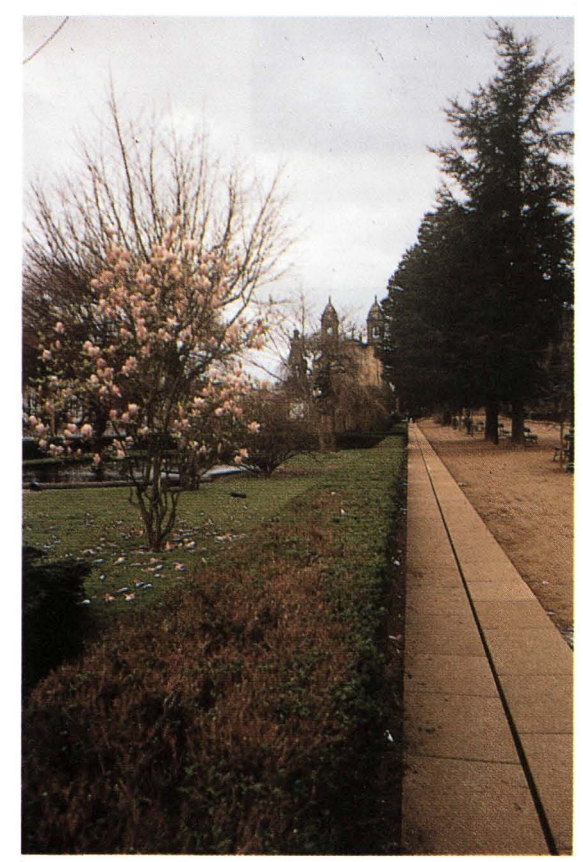

Fig. 21.- Sumidero longitudinal.

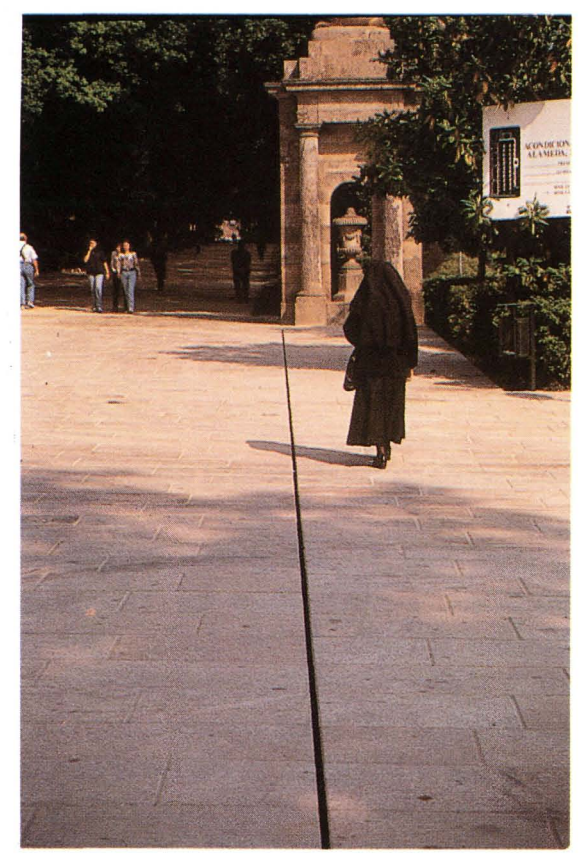

Fig. 22.- Plaza de acceso al paseo de los Leones. las redes de saneamiento, riego y alumbrado y el extendido de un nuevo pavimento de jabre estabilizado.

\section{Tierra y Piedra}

La Alameda y el Paseo de la Herradura son el soporte de numerosas actividades ciudadanas que necesitan el acceso ocasional de todo tipo de vehículos. Este uso intensivo, unido al régimen de precipitaciones de esta ciudad, difícilmente se compatibiliza con el mantenimiento del

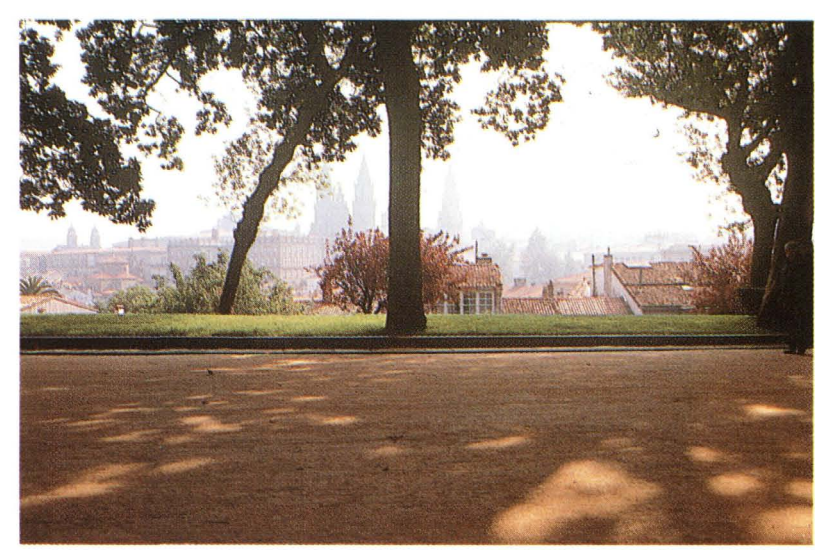

Fig. 23.- Paseo de los Leones.

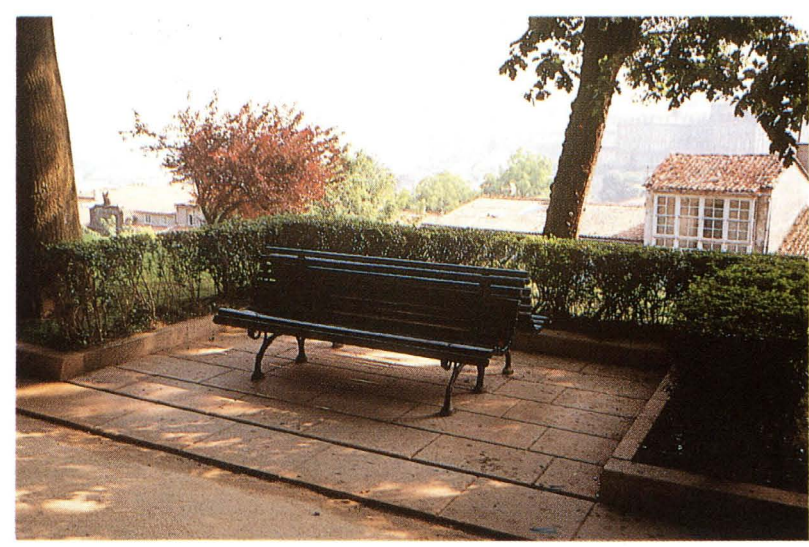

Fig. 24.-Paseo de los Leones. 


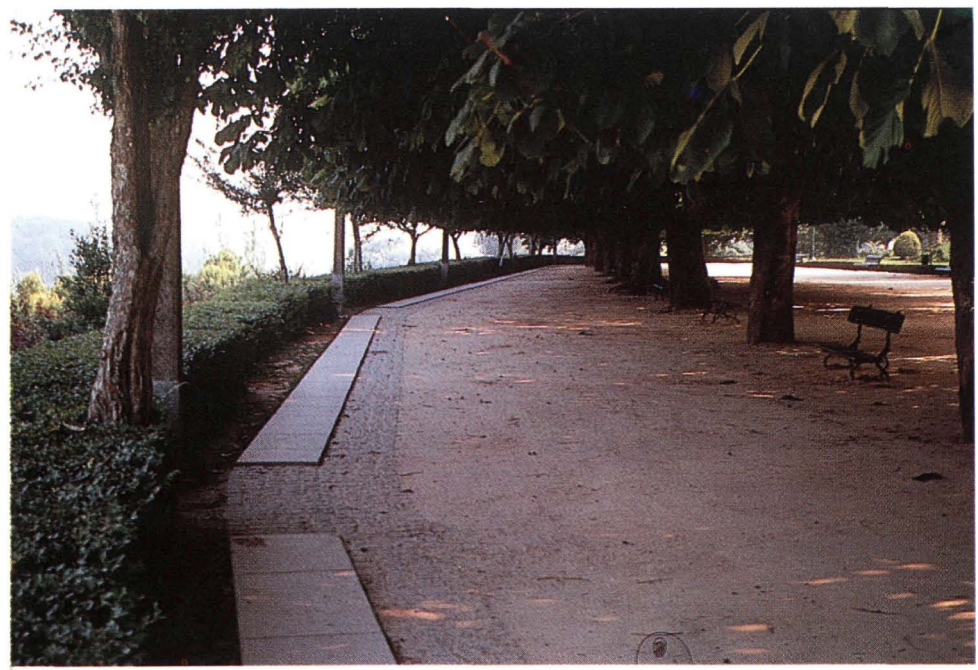

Fig. 25.- Paseo de la Herradura.

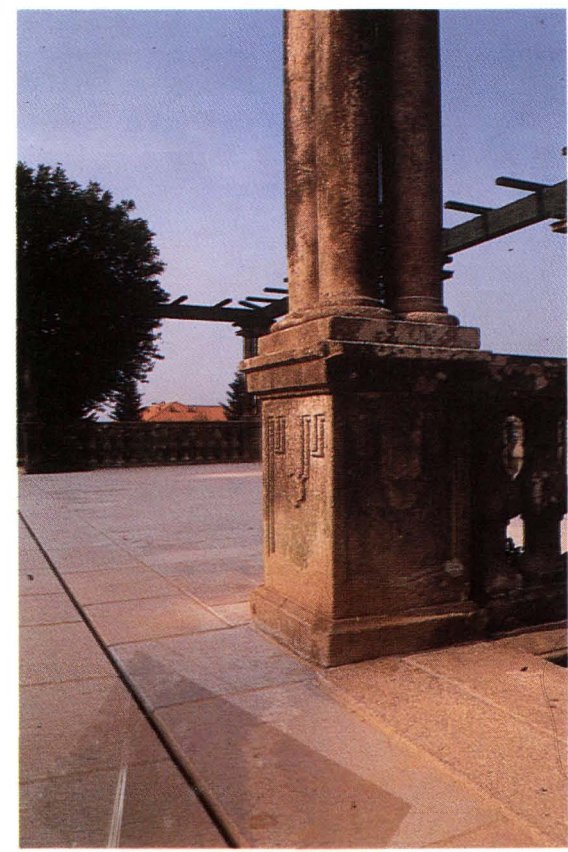

Fig. 26.- Paseo de la Herradura. Mirador sobre el campus.

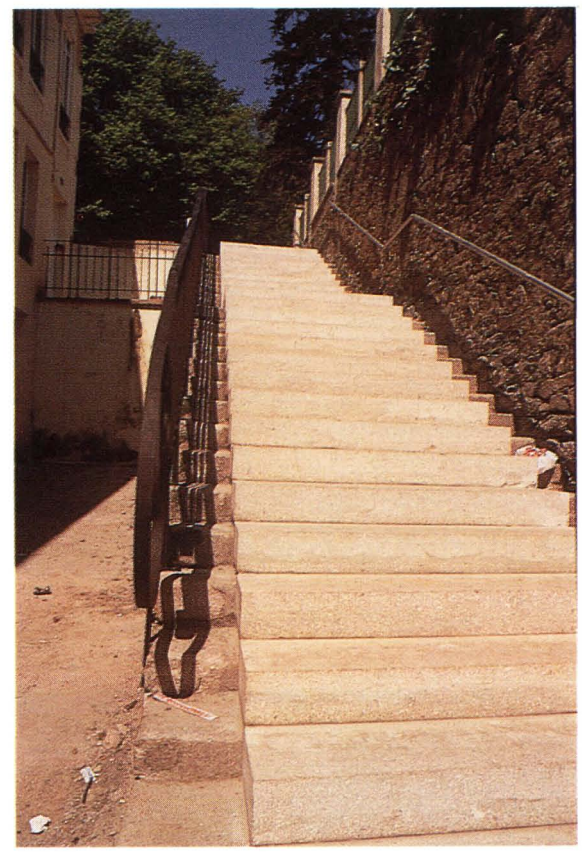

Fig. 27.-Comunicación entre el paseo de la Herradura y la avda. Juan Carlos I tradicional firme de tierra. Por ello se estudióla posibilidad de estabilizar el jabre con la adición de cemento blanco, garantizando el mantenimiento del color y aspecto característico de este tipo de suelos.

Una vez elegido el jabre y realizados los ensayos correspondientes, se determinó que la dosificación más favorable se obtenía con un 7,5\% de cemento II-B/45A sobre el peso del suelo seco y un $12 \%$ de humedad sobre la mezcla seca, obteniéndose una resistencia a los siete días en torno a los $30 \mathrm{~kg} / \mathrm{cm}^{2}$.
La piedra empleada en las obras es el denominado "granito silvestre", aserrado en piezas de ancho uniforme y largo libre. Este tipo de corte permite el máximo aprovechamiento del material, e introduce un cierto grado de indeterminación (propio de los pavimentos de piedra tradicionales), al depender el aspecto final del enlosado del criterio y habilidad de los canteros, cuando eligen' y combinan el color y longitud de las losas de piedra. Las aristas de la cara vista se biselan de forma que la llaga quede rehundida medio centímetro, evitanđo el esportillado de las mismas a la vez que se favorece la evacuación del agua. 
Por último, señalar que los dos proyectos descritos confian más en la expresividad de los materiales, en los trazados y referencias implícitos en la forma urbana preexistente, que en el uso de estrategias formales sofisticadas. Esta actitud obliga a la utilización de pocas partículas expresivas localizadas con precisión y al máximo cuidado del detalle, que se convierte así en el significante más poderoso.

\section{Fichas Técnicas}

Obra: Acondicionamiento de las riberas del Sarela en el Carmen D'abaixo.

Promoción: Concello de Santiago.

Redacción del Proyecto: José Luis Pérez Franco, Arquitecto.

Dirección de Obra: José Luis Pérez Franco, Arquitecto y Juan Fernández Ferreiro, Aparejador.

Fotografia: José Luis Pérez Franco y Luís Alonso Lamberti.

Empresa Constructora: P.A.M. Concello de Santiago.

Presupuesto de Contrata: 22.725 .573 ptas.

Duración de las Obras: 5 meses.

Obra: Acondicionamiento de los Paseos de la Alameda, Herradura y Coto de Santa Susana.

Promoción: Consorcio de Santiago.

Redacción del Proyecto: José Luís Pérez Franco, Arquitecto.

Dirección de Obra: José Luis Pérez Franco, Arquitecto y José Carlos López Vila, Aparejador.

Fotografía: José Luis Pérez Franco y Haydée Estévez Barcala.

Empresa Constructora: Ferrovial.

Presupuesto de Contrata: 173.913 .038 ptas.

Duración de las Obras: 8 meses. 